\title{
An examination, with a meta-analysis, of studies of childhood leukaemia in relation to population mixing
}

\author{
LJ Kinlen*,I \\ 'Cancer Epidemiology Unit, University of Oxford, Richard Doll Building, Headington, Oxford OX3 7LF, UK
}

\begin{abstract}
BACKGROUND: Marked influxes of people into rural areas, termed rural population mixing (PM), have been associated with excesses of childhood leukaemia (CL), consistent with mini-epidemics of a mainly immunising, subclinical infection to which $C L$ is a rare response. For such situations of rural PM would promote contacts between infected and susceptible individuals, the latter tending to have a higher than average prevalence in rural or isolated areas. Confusion has arisen from some workers applying the term PM to non-rural situations lacking known recent change.

METHODS: Available PM studies using the original definition of influxes were examined, a meta-analysis carried out of studies of CL in relation to exposure to high levels of rural PM, and also a detailed analysis by age group.

RESULTS: The meta-analysis of 17 studies shows a significant CL excess in association with rural PM: overall relative risk (RR) at ages 0-14: 1.57; 95\% confidence interval 1.44-1.72; at 0-4 years I.72 (I.54-1.9I). This contrasts with the absence of an excess of CL in similarly exposed urban areas (RR I.00; 0.93-1.07), pointing to a high level of immunity there. The mixed results of studies using other definitions of PM were summarised. The excess associated with rural PM below age 2 years (RR I.5।; I. I7, I.92) was not appreciably different from that at later childhood ages.

CONCLUSION: Much of the inconsistency among studies ostensibly about CL and PM reflects the use of definitions other than that originally proposed. The broad similarity of the CL excess below age 2 with that at older childhood ages is inconsistent with the Greaves' delayed infection hypothesis, since any infection underlying the former is difficult to consider as delayed.

British Journal of Cancer (2012) I 07, I | 63-| | 68. doi:I0.1038/bjc.20 I2.402 www.bjcancer.com

Published online 6 September 2012

(C) 2012 Cancer Research UK
\end{abstract}

Keywords: childhood leukaemia; population mixing; meta-analysis; infection

The question of an infective basis in childhood leukaemia (CL) was re-opened over 20 years ago following the observation that certain well-known excesses in remote areas of Britain were explicable in terms of classical infectious disease epidemiology, and a series of studies initiated (Kinlen 1988, 2011; Kinlen et al, 1990). The absence of marked space-time clustering excludes contagion of CL itself, so that any underlying infection would belong to that large group where transmission is mainly subclinical, and illness a rare response; such infections, which include those by polioviruses, EBV, besides other oncogenic viruses, are mainly immunising. A high prevalence of the relevant infection, as for example in areas of high population density, would limit the scope for epidemics to occur and hence of increases in incidence of the uncommon leukaemogenic response. However, marked influxes of people into rural areas would be conducive to epidemics of the underlying infection, and therefore to excesses of CL. In such areas, their lower population density would have tended to raise the level of susceptible individuals, making those areas more 'sensitive' to the effects of influxes of outsiders. For the increased population density produced by a marked rural influx would promote new contacts between susceptible and infected individuals.

The rural situations mentioned above were summarily referred to as population mixing (PM), the context making clear its special

*Correspondence: Professor LJ Kinlen; E-mail: leo.kinlen@gtc.ox.ac.uk Received 25 May 2012; revised 26 July 2012; accepted 8 August 2012; published online 6 September 2012 sense, of the increase in population density produced by a marked influx into a rural area. Schools, and even urban areas generally, broadly involve 'population mixing', but not in the sense used here. However, the term PM has recently been applied to high levels of 'house movers' or 'migrants', often in largely urban areas lacking known population change. The varied findings of ensuing studies have tended to confuse the subject, and an examination of PM studies in the light of the definition used was considered appropriate.

\section{MATERIALS AND METHODS}

A literature search was conducted using the terms 'population mixing', population influx, 'childhood leukaemia', and 'acute lymphoblastic leukaemia' (ALL); in addition, references in the papers identified were checked for any that had been overlooked. In some cases, CL had been combined with non-Hodgkins lymphoma (NHL). When findings for both CL and ALL were presented, the latter were preferred. The first epidemiological mention of PM that could be traced was in 1990 (by the writer), but earlier CL literature back to 1965 was searched for mentions of population influx. From over 60 studies of possible relevance, the following were excluded, studies: (i) of migrant prevalence at single (census) points in time; (ii) those that did not separate rural from urban PM; (iii) of non-residential mixing, such as increases of commuting-to-work, or the mixing associated with attendance at child-care units; or (iv) without relevant observed and expected numbers of CL; (v) of pronounced CL clusters that were noticed 
outside a formal study (except for any excess persisting after investigation had begun); (vi) of high levels of paternal occupational contacts in the absence of population increase. In the first of the above exclusions (i), particular note was taken of reports that concerned CL in relation to the prevalence of individuals resident elsewhere a year before a census, as these included PM in the title.

Because of the selection criteria, certain studies were excluded despite their reporting CL excesses associated with PM, because of the absence of a separate analysis for rural areas. This applied to the report by Langford (1991a) of higher CL mortality in local authority districts of England and Wales that increased in population by $>50 \%$ in the decade 1961-1971; this CL increase was stated to be greater in rural districts (Langford, 1991b), but the relevant analysis was not provided. Certain other papers also failed to report on rural areas separately (Infante-Rivard et al, 2000; Nyari et al, 2006). The extreme disruption caused by civil war is likely to cause rural PM, but the reported excesses associated with the wars in Greece and Croatia could not be included here as, again, analyses were not available separating rural from urban areas (Kinlen and Petridou 1995; Labar et al, 2004). Two US studies that found some evidence of CL excess in relation to population increase are also not included for a similar reason (Adelman et al, 2007; Clark et al, 2007).

In the first studies that were national in scope, rural was compared with urban PM of similar degree, and these latter were included in this study as a separate category, to which was added a study of metropolitan Taiwan (Li et al, 1998). For two other studies, the authors were contacted for additional information: for the Fallon cluster, to determine the ages of cases, and whether they occurred in the town itself (Steinmaus et al, 2004), and for Hong Kong growth areas, to obtain the expected value for CL in the rural new town that expanded more, and for longer, than any other tertiary planning unit (Alexander et al, 1997). To be conservative, the study of French growth communes (with no CL increase; Laplanche and de Vathaire, 1994) was classed as involving rural $\mathrm{PM}$, despite uncertainty as to whether the communes in question approximated to rural or to urban (overspill) new towns in Britain (Kinlen, 1994). Overlap between study bases was avoided, and for this reason the first PM study, of Kirkcaldy rural (landward) district (Kinlen, 1988), was excluded, as it was largely covered by Glenrothes in the study that followed of British new towns (Kinlen et al, 1990).

For studies that involved graded categories of PM exposure, relative risks (RRs), with confidence intervals (CIs), were extracted for ages $0-4$ and $0-14$ years for the highest PM exposure category relative to the lowest. Corresponding risks relative to national rates were abstracted from other studies, such as that of new towns, where results were presented for a single category; the findings of both types of study were also combined. A meta-analysis was then carried out using a weighted average of the study-specific log RRs, the weights being proportional to the inverse of the variances of the log RRs. Tests of heterogeneity were also conducted.
As exposures below age two have particular relevance to another hypothesis (Greaves, 1988), data for CL at these ages were separated where possible from older childhood years.

\section{RESULTS}

In total, 18 studies of CL in relation to marked PM were accepted as involving population increase as in the original definition, 10 in the United Kingdom, and 8 in other countries; half of these were mortality (numbered $1-4,6,8,11$, and 14 in the figures), the rest were incidence studies. Table 1 shows the mixed results of studies excluded from the meta-analysis because they lacked known population increase. The findings in each of the 17 rural PM studies are presented in Figure 1, including RRs (and 95\% CIs) at ages $0-14$ and 0-4 years, separating those in which the highest exposure categories is shown relative to the lowest. The overall RRs for $\mathrm{CL}$ at ages $0-14$ and $0-4$ associated with marked rural PM were 1.57 (1.44-1.72) and $1.72(1.54-1.91)$, respectively. Figure 2 shows that no overall excess was found in the high exposure category of seven studies of marked urban PM, the RRs at ages $0-14$ and $0-4$ being $1.00(0.93-1.07)$ and $1.00(0.91-1.11)$, respectively. In six of the latter, the high PM exposure was of similar degree to that in rural parts of the same study as included in Figure 1.

Test for heterogeneity were carried out and included in the figures; funnel plots were also examined. There was significant heterogeneity both among rural and urban PM studies, with some evidence from funnel plots consistent with publication bias. This, however, would also be consistent with there being unusually high levels of susceptible individuals in association with extreme PM in certain populations, and there was support for this possibility. The three outlying studies of rural PM were of Fallon, Seascale, and the rural new town of extreme growth in the New Territories are discussed later under 'dose-response' relations. Their exclusion slightly reduced the overall RR in Figure 1 at ages $0-14$ to 1.53 (1.40-1.67), and at $0-4$ years to 1.68 (1.51-1.87). The outlying urban PM study was that by Li et al (1998) in which influxes into metropolitan Taiwan were described as originating in rural areas.

Table 2 shows CL data below age 2 years separately from other ages. No appreciable difference is evident in the CL excess at 0 and 1 year (RR $1.51 ; 1.17,1.92)$ from that in later childhood age groups.

\section{DISCUSSION}

The present examination of CL studies in relation to pronounced increases in local population and density finds an overall significant association between marked rural PM of this type and CL excess; in contrast, no overall excess was found in relation to $\mathrm{PM}$ in urban areas. It may be noted that it was never suggested that $\mathrm{PM}$ was the main, far less the only, situation for transmission of an underlying infection, but merely that it was likely to promote miniepidemics, and was testable.

Table I The findings in studies of $\mathrm{CL}$ in relation to PM - defined as the prevalence (MP) and/or diversity of origin (DO) of migrants at a single (census) point in time

\begin{tabular}{|c|c|c|c|c|c|c|}
\hline \multirow[b]{2}{*}{ Reference: first author (year) } & \multirow[b]{2}{*}{ Country } & \multirow[b]{2}{*}{ Areal unit } & \multicolumn{3}{|c|}{ CL findings in areas with high } & \multirow[b]{2}{*}{ Urban (U) or Rural (R) } \\
\hline & & & MP & DO & Both MP and DO & \\
\hline Stiller (1996) & $E-W$ & CDs & NS & NS & Excess & ND \\
\hline Parslow (2002) & E (Yorks) & Wards & NS & NS & Deficit & ND \\
\hline Law (2003) & Britain & Wards & NS & (Excess with low DO) & NS & ND \\
\hline Rudant (2006) & France & a & Excess & NS & NS & $\mathrm{R}$ \\
\hline
\end{tabular}

Abbreviations: $\mathrm{CL}=$ childhood leukaemia; $\mathrm{CD}=$ County district; $\mathrm{ND}=$ not distinguished; $\mathrm{NS}=$ nil significant; PM= population mixing; Yorks $=$ Yorkshire. ${ }^{\text {a }}$ Communes (at time of birth). 

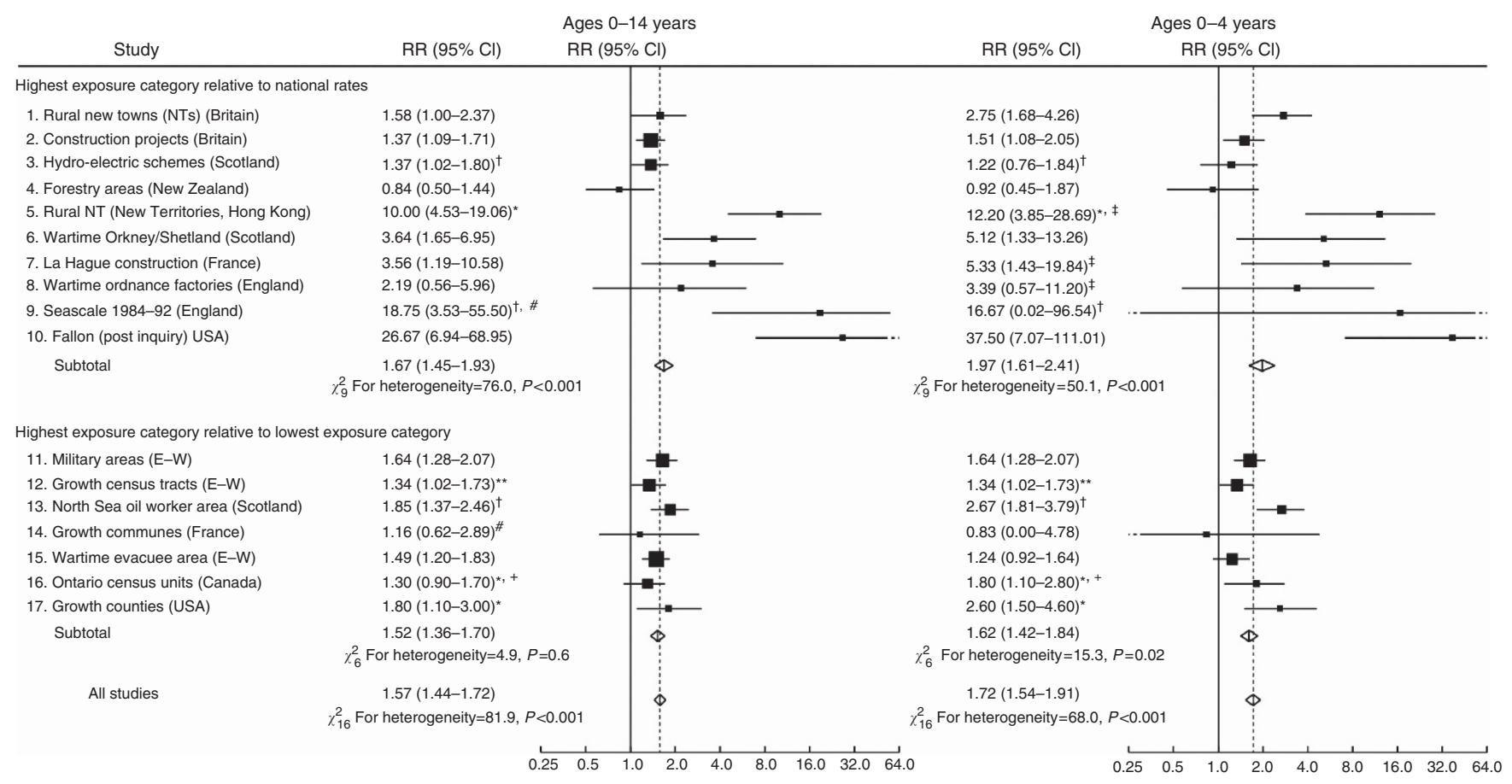

Figure I Marked rural PM and CL.

*Acute lymphocytic leukaemia; "includes NHL; ***lymphocytic and unspecified leukaemia; ${ }^{*}$ ages 0-24; ${ }^{\ddagger}$ data for $0-4$ not available, instead, study 5 refers to 2-6 years, study 7 to $\mathrm{I}-6$ years, and study 8 to $\mathrm{I}-4$ years. $\mathrm{Cl}=$ confidence interval; $\mathrm{E}-\mathrm{W}=$ England and Wales; $\mathrm{RR}=$ relative risk. ${ }^{+} \mathrm{RR}$ and $\mathrm{Cl}$ given to one decimal place. Key: I. Kinlen et al, 1990; 2 and 3. Kinlen et al (1995); 4. Dockerty et al (1996); 5. Alexander et al (1997) Alexander (2006); 6. Kinlen and Balkwill (200I); 7. Boutou et al (2002); 8. Kinlen (2006); 9. COMARE (1996); I0. Todd, 2004; US Bureau of Census; II. Kinlen and Hudson (I99I); I2. Rodrigues et al (199I); I3. Kinlen et al (1993); I4. Laplanche and de Vathaire (1994); I5. Kinlen and John (I994); and I6. Koushik et al (200 I); Wartenberg et al (2004).

\section{Definition of PM}

The variety of examples of PM of the above type included in this study does not lend itself to a tidy description - some being qualitatively striking (e.g., the creation of new towns, or large construction projects), others qualitatively so (the top tertile or quintile of a national ranking of areas in terms of, for example, servicemen, evacuees, or oil workers). Some confusion has arisen through some workers defining PM differently from that originally proposed (Stiller and Boyle, 1996; Dickinson et al, 2002; Parslow et al, 2002; Law et al, 2003; Rudant et al, 2006; Stiller et al, 2008). In contrast to the situations of striking rural change associated with increases in population density shown in Figure 1, these six studies (see Table 1) focussed on areas, often largely urban, without recent known population increase, but with a high level, and diversity of origin, of 'migrants' (persons resident elsewhere a year before, a standard census item). Moving house, or population turnover, is frequent in modern life, and largely represents a form of 'changing places': a high level implies nothing about any population increase. The authors of four of the above six papers have further emphasised their approach in a paper entitled 'What do epidemiologists mean by population mixing', which states that 'Kinlen's original concept has been extended to investigating mixing at a more general level..' (Law et al, 2008). However, the rationale for ignoring crucial aspects of the original definition was not discussed.

Most of the CL excesses associated with rural PM shown in Figure 1 were of limited duration, and detected by examining the periods during or immediately after documented examples of PM. They would not have been reliably detected by focussing on single time points bearing an unknown relation to the period of change. Perhaps predictably, the results of this approach have been mixed. It is change that begets change. The important role of changes in population density (or crowding) in producing epidemics in humans and animals has been stressed (Anderson and May, 1979, 1982; Miles, 1983; Kinlen et al, 1990). The lack of effect of urban mixing, demonstrated in the first five PM studies, was also predicted, and yet negative results from migrant studies in mainly urban areas at single time points (Table 1) have been offered as evidence against the hypothesis. Thus, a report by the UK Childhood Cancer Study (UKCCS) that was linked in its opening to the striking Fallon cluster, used ward data from the 1991 census to argue that PM (of undated onset, and defined as a high diversity of migrant origins) was associated, not with any excess but, with protection from CL (Law et al, 2003).

\section{Rural-urban differences}

The fact that comparable degrees of mixing in urban areas do not show CL excesses suggests the presence there of high levels of herd immunity; in such areas, the relative lack of susceptible individuals would not favour epidemics of the underlying infection, which instead shows a sporadic pattern of infection and of its uncommon complication, CL. Observations of differences in the pattern of infections between rural and urban areas have a long history in epidemiology. Thus, in 1917 when the United States mobilised an army in the First World War, the US Army Medical Service were given unusual opportunities for observing the development of epidemics in crowded communities; striking differences were noted among the camps. Those with recruits drawn from the sparsely settled states had far more epidemics (of mumps, measles, lobar pneumonia, meningococcal meningitis, and scarlet fever) than camps (often situated nearby) with city-bred recruits (Love and Davenport, 1919). There are here parallels with infection by polioviruses and (in cats) feline leukaemia virus, in which contrasting effects occur in social settings differing in population density. 


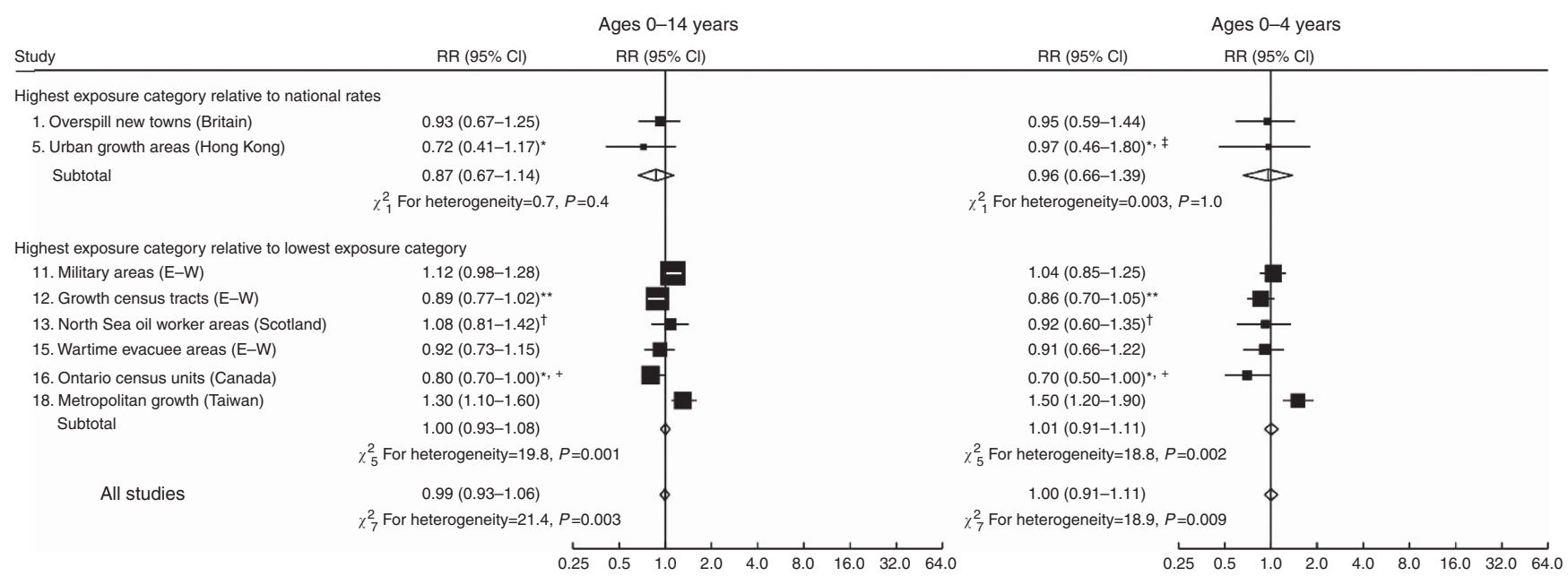

Figure 2 Marked urban PM and CL.

*Acute lymphocytic leukaemia; ${ }^{\dagger}$ includes $\mathrm{NHL}$; ${ }^{*} *$ lymphocytic and unspecified leukaemia; ${ }^{\ddagger}$ ages $2-6$ years. E-W $=$ England and $\mathrm{Wales}$. $\mathrm{Cl}=$ confidence interval; $\mathrm{RR}=$ relative risk. ${ }^{+} \mathrm{RR}$ and $\mathrm{Cl}$ given to one decimal place. Key: study numbers as in Figure I; I8. Li et al, 1998.

Table 2 Studies of CL and rural PM, separating ages 0-I years from later age groups: observed (and expected) numbers

\begin{tabular}{|c|c|c|c|c|}
\hline Rural study areas ${ }^{a}$ & $0-1$ Years & 2-4 Years & 5-14 Years & $0-14$ Years \\
\hline Military areas (II) & $20(8.96)$ & $23(13.45)$ & $28(20.88)$ & $71(43.29)$ \\
\hline Oil worker areas (13) & $10(4.65)$ & $21(6.97)$ & $17(14.34)$ & $48(25.96)$ \\
\hline Construction projects ( 2 and 3 ) & $19(12.45)$ & $44(27.15)$ & $67(49.55)$ & $130(94.80)$ \\
\hline Wartime Orkney/Shetland (6) & $2(0.20)$ & $2(0.58)$ & $5(1.69)$ & $9(2.47)$ \\
\hline Total & $68(44.96)$ & $142(76.19)$ & $161(115.23)$ & $371(242.08)$ \\
\hline
\end{tabular}

Abbreviations: $\mathrm{Cl}=$ confidence interval; $\mathrm{CL}=$ childhood leukaemia; $\mathrm{E}=$ expected; $\mathrm{O}=$ observed; $\mathrm{PM}=$ population mixing. ${ }^{\mathrm{a}} \mathrm{Study}$ numbers as in Figure I.

\section{'Dose-response' relations}

The types of rural PM studied have been most varied - children evacuated away from urban centres in wartime, the military occupation of Orkney and Shetland in the war, post war increases of national servicemen, new towns, and major construction projects, including the North Sea oil industry. This variety makes it difficult to investigate exposure-response relations, though it is striking that the two largest excesses, in Seascale and Fallon, occurred after rural PM of exceptional degree and, moreover, in isolated places where susceptible individuals would be prevalent. The building near Seascale in North-West England of the Thermal Oxide Reprocessing Plant at Sellafield in 1984-1992 by a workforce of up to 50000 represented perhaps the largest construction project in England since the war; it was associated with a $>16$-fold increase of CL and NHL at ages 0-4 and 0-24 (COMARE, 1996). In the US desert town of Fallon, Nevada (population 7000), a 37-fold increase of CL occurred just after the annual throughput of recruits at the nearby naval air-base reached a record high level of 50000 in 2000 (Kinlen and Doll, 2004; Steinmaus et al, 2004; Todd, 2004, personal communication). In both these examples, the CL estimates quoted are based only on the cases that occurred after the start of official enquiry, as these cases are free of the bias implicit in applying statistical tests post hoc. Among British rural new towns, the three towns whose population grew 42fold (over a 16-year period) experienced a greater excess (RR 2.62; $1.39,4.49)$ than the other new towns that grew only 3.2-fold (RR 1.04; 0.49, 1.92; Kinlen et al, 1990).

\section{The Greaves' hypothesis}

The hypothesis underlying the PM studies of CL shown in Figure 1, of a specific infection (as in the great majority of infective disorders that are understood), most probably viral, is often linked, or contrasted, with the immunological hypothesis of Greaves (1988). This attributes common ALL to mutations in lymphocytes rendered vulnerable through delayed exposure to infection in the first 2 years of life. Rural PM must often first expose susceptible rural children to infection $<2$ years of age, therefore representing a 'delayed' exposure. For this reason, the excesses observed in association with $\mathrm{PM}$ appear also to support the Greaves' hypothesis; from this perspective, the hypotheses can be seen as differing mainly in the mechanisms postulated (e.g., Greaves, 1997; Gilham et al, 2005). In the case of $\mathrm{CL}<2$ years of age, however, the relevant exposure can hardly be considered 'delayed', so an analysis was carried out to examine this age group separately (Table 2 ). The fact that no appreciable difference was found in the CL excess below age 2 from that later in childhood is inconsistent with the Greaves' hypothesis. The findings of the major UKCCS, mentioned above, were initially considered to support this hypothesis (Law et al, 2003), until it was pointed out by Tucker (2004) that in fact they contradicted it. This was later acknowledged by the investigators, who reported that infections in the first year of life were associated, not with protection, but with a significant excess of CL (Roman et al, 2007). 


\section{CONCLUSION}

Novel aspects of this study include the meta-analysis, and showing that much of the apparent inconsistency among studies ostensibly of 'population mixing' comes from studies using a definition of PM substantially different from that originally proposed. An examination of studies using the latter shows a significant association of CL

\section{REFERENCES}

Adelman AS, Groves FD, O'Rourke K, Sinha D, Hulsey TC, Lawson AB, Wartenberg D, Hoel DG (2007) Residential mobility and risk of childhood lymphoblastic leukaemia: an ecological study. $\mathrm{Br} \mathrm{J}$ Cancer 97: $140-144$

Alexander FE (2006) Personal communication

Alexander FE, Chan LC, Lam TH, Yuen P, Leung NK, Ha SY, Yuen HL, Li CK, Li CK, Lau YL, Greaves MF (1997) Clustering of childhood leukaemia in Hong Kong: association with the childhood peak and common acute lymphoblastic leukaemia and with population mixing. $\mathrm{Br} J$ Cancer 75: 457-763

Anderson RM, May RM (1979) Population biology of infectious diseases: part 1. Nature 280: 361-367

Anderson RM, May RM (1982) Directly transmitted infectious diseases; control by vaccination. Science 215: 1053-1060

Boutou O, Guizard AV, Slama R, Pottier D, Spira A (2002) Population mixing and leukaemia in young people around the La Hague nuclear waste reprocessing plant. $\mathrm{Br}$ J Cancer 87: 740-745

Clark BR, Ferketich AK, Fisher JL, Ruymann FB, Harris RE, Wilkins JR (2007) Evidence of population mixing based on the geographical distribution of childhood leukemia in Ohio. Pediatr Blood Cancer 49: 797-802

Committee on Medical Aspects of Radiation in the Environment (COMARE) (1996) Fourth Report. The incidence of cancer and leukaemia in young people in the vicinity of the Sellafield site, West Cumbria: further studies and an update of the situation since the publication of the report of the Black Advisory Group in 1984. Department of Health: Wetherby, UK

Dickinson HO, Hammal DM, Bithell JF, Parker L (2002) Population mixing and childhood leukaemia and non-Hodgkin's lymphoma in census wards in England and Wales, 1966-87. Br J Cancer 86: 1411-1413

Dockerty JD, Cox B, Borman B, Sharples K (1996) Population mixing and the incidence of childhood leukaemias: retrospective comparison in rural areas of New Zealand. BMJ 312: 1203-1204

Gilham C, Pet J, Roman E, Eden TOB, Greaves MF, Alexander FE, for the UKCCS investigators (2005) Day care in infancy and risk of childhood acute lymphoblastic leukaemia: findings from UK case-control study. BMJ 330: 1294-1299

Greaves MF (1988) Speculations on the cause of childhood acute lymphoblastic leukaemia. Leukaemia 2: 120-125

Greaves MF (1997) Aetiology of acute leukaemia. Lancet 349: 344-349

Infante-Rivard C, Fortier I, Olson E (2000) Markers of infection, breastfeeding and childhood acute lymphoblastic leukaemia. $\mathrm{Br} J$ Cancer 83: $1559-1564$

Kinlen L (1988) Evidence for an infective cause of childhood leukaemia: comparison of a Scottish New Town with nuclear reprocessing sites in Britain. Lancet ii: $1323-1327$

Kinlen L (2006) Childhood leukaemia and ordnance factories in west Cumbria during the Second World War. Br J Cancer 95: 102-106

Kinlen L (2011) Childhood leukaemia, nuclear sites, and population mixing. Br J Cancer 104: 12-18

Kinlen L, Doll R (2004) Population mixing and childhood leukaemia: Fallon and other US clusters. Br J Cancer 91: 1-3

Kinlen LJ (1994) Leukaemia mortality among young people in growing French communes. Br J Cancer 70: 180

Kinlen LJ, Balkwill A (2001) Infective cause of childhood leukaemia and wartime population mixing in Orkney and Shetland, UK. Lancet 357: 858

Kinlen LJ, Clarke K, Hudson C (1990) Evidence from population mixing in British New Towns 1946-85 of an infective basis for childhood leukaemia. Lancet 336: 577-582

Kinlen LJ, Dickson M, Stiller CA (1995) Childhood leukaemia and nonHodgkin's lymphoma near large rural construction sites, with a comparison with Sellafield nuclear site. BMJ 310: 763-768 excess with marked rural, but not with urban, PM. The PM and Greaves' hypotheses are not infrequently seen as providing alternative explanations for the same CL excesses, but in PM studies, the similarity of the excess below age 2 to that at older childhood ages is inconsistent with the latter hypothesis.

Kinlen LJ, Hudson C (1991) Childhood leukaemia and poliomyelitis in relation to military encampments in England and Wales in the period of national military service, 1950-63. BMJ 303: 1357-1362

Kinlen LJ, John SM (1994) Wartime evacuation and mortality from childhood leukaemia in England and Wales in 1945-9. BMJ 309: $1197-1202$

Kinlen LJ, O'Brien F, Clarke K, Balkwill A, Matthews F (1993) Rural population mixing and childhood leukaemia: effects of the North Sea oil industry in Scotland, including the area near Dounreay nuclear site. BMJ 306: 743-748

Kinlen LJ, Petridou E (1995) Childhood leukaemia and rural population movements: Greece, Italy, and other countries. Cancer Causes Control 6: $445-450$

Koushik A, King WD, McLaughlin JR (2001) An ecologic study of childhood leukaemia and population mixing in Ontario, Canada. Cancer Causes Contr 12: 483-490

Labar B, Rudan I, Ivankovic D, Biloglav Z, Mrsic M, Strnad M, Fucic A, Znaor A, Bradic T, Campbell H (2004) Haematological malignancies in childhood in Croatia: investigating the theories of depleted uranium, chemical plant damage and 'population mixing'. Eur J Epidemiol 19: 55-60

Langford I (1991a) Childhood leukaemia mortality and population change in England and Wales 1969-73. Soc Sci Med 33: 435-440

Langford I (1991b) Infection and Childhood Leukaemia, PhD thesis. University of East Anglia, Norwich, UK

Laplanche A, de Vathaire F (1994) Leukaemia mortalty in French communes (administrative units) in a large and rapid population increase. Br J Cancer 69: 110-113

Law GR, Feltblower RG, Taylor JC, Parslow RC, Gilthorpe MS, Boyle P, McKinney PA (2008) What do epidemiologists mean by 'Population mixing'? Pediatr Blood Cancer 51: 155-160

Law GR, Parslow RC, Roman E, on behalf of the UK Childhood Cancer Study Investigators (2003) Childhood cancer and population mixing. Am J Epidemiol 158: 328-336

Li C-Y, Lin RS, Lin C-H (1998) Urbanization and childhood leukaemia. Int J Epidemiol 27: 587-591

Love AG, Davenport CB (1919) Immunity of city-bred recruits. Arch Intern Med 24: 129-153

Miles A (1983) Herd infection and herd immunity. In Topley and Wilson. Principles of Bacteriology, Virology and Immunity, Wilson G, Miles A, Parker MT (eds) 7th edn, Vol. 1, pp 413-428. Edward Arnold: London

Nyari TA, Kajtar P, Bartyik K, Thurzo L, Parker L (2006) Childhood acute lymphoblastic leukaemia in relation to population mixing around the time of birth in South Hungary. Pediatr Blood Cancer 47: 944-948

Parslow RC, Law GR, Feltblower R, Kinsey SE, McKinney PA (2002) Population mixing, childhood leukaemia, CNS tumours and other childhood cancers in Yorkshire. Eur J Cancer 38: 2033-2040

Rodrigues L, Hills M, McGale P, Elliott P (1991) Socio-economic factors in relation to childhood leukaemia and non-Hodgkin lymphomas: an analysis based on small area statistics for census tracts. In The Geographical Epidemiology of Childhood Leukaemia and Non-Hodgkins Lymphoma in Great Britain, 1966-83. Studies on Medical and Population Subjects, Draper G (ed), Number 53, pp 47-56

Roman F, Simpson J, Ansell P, Kinsey S, Mitchell CD, McKinney PA, Birch JM, Greaves M, Eden T, on behalf of the United Kingdom Childhood Cancer Study Investigators (2007) Childhood acute lymphoblastic leukaemia and infections in the first year of life: a report from the United Kingdom Childhood Cancer Study. Am J Epidemiol 165: 496-504

Rudant J, Boccaini B, Ripert M, Goubin A, Bellec S, Hemon D, Clavel J (2006) Population mixing at the place of residence at the time of birth and incidence of childhood leukaemia in France. Eur J Cancer 42: 927-933

Steinmaus C, Lu M, Todd RL, Smith AH (2004) Probability estimates for the unique childhood leukemia cluster in Fallon, Nevada, and risks near other US military aviation facilities. Environ Health Perspect 112: 766-771 
Stiller CA, Boyle PJ (1996) Effect of population mixing and socioeconomic status in England and Wales, 1979-85, on lymphoblastic leukaemia in children. BMJ 313: 1297-1300

Stiller CA, Kroll ME, Boyle PJ, Feng Z (2008) Population mixing, socioeconomic status and incidence of childhood leukaemia in England and Wales: analysis by census ward. Br J Cancer 98: 1006-1011
Todd RL (2004) Personal communication

Tucker MA (2004) Population mixing. Am J Epidemiol 159: 716-717

Wartenberg D, Schneider D, Brown S (2004) Childhood leukemia incidence and the population mixing hypothesis in US SEER data. Br J Cancer 90: 1171-1776

This work is published under the standard license to publish agreement. After 12 months the work will become freely available and the license terms will switch to a Creative Commons Attribution-NonCommercial-Share Alike 3.0 Unported License. 